\title{
A NEW SPINAL INJURIES CENTRE AT IIZUKA CITY IN JAPAN
}

\author{
By Takashi Akatsu, M.D. \\ Director Spinal Injuries Centre, Iizuka City, Fukuoka, fapan.
}

THE new Spinal Injuries Centre at Iizuka City was officially opened on 2 I May 1979. It is administrated by the Japanese Labour Welfare Projects Corporation.

Five years ago Professor Tamikazu Amako was requested by the Ministry of Labour of the Japanese Government to advise in the planning of the new Spinal Injuries Centre in Japan, the centre being developed within 3 years. It has complete facilities for all the immediate medical and surgical management needs of paraplegics and tetraplegics. In addition to these medical facilities a vocational rehabilitation unit, a rehabilitation engineering unit, outstanding therapeutic and recreational facilities for indoor and outdoor sports (sports stadium and swimming pool) are provided. A heliport is also available to facilitate immediate transportation for those who need treatment.

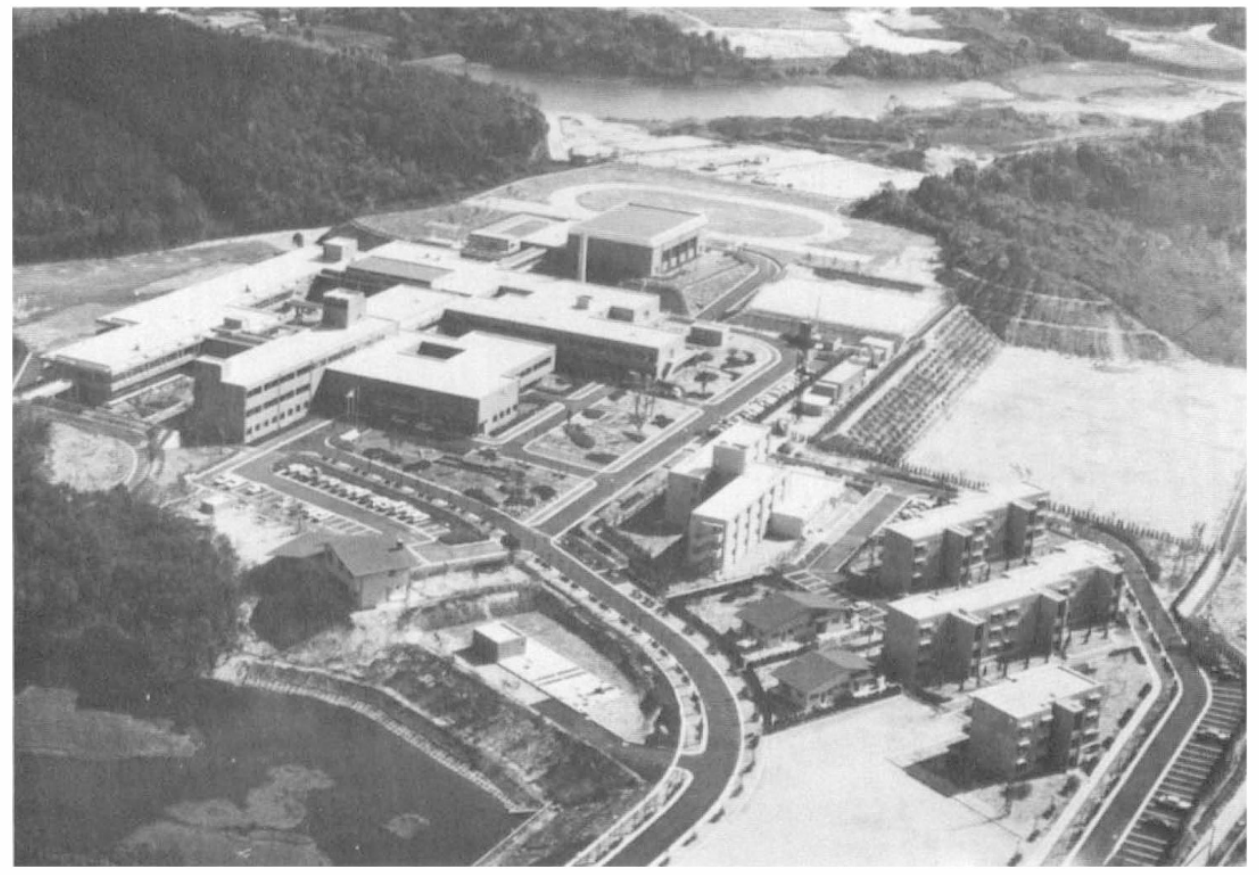

FIG. I

Panoramic view of the Spinal Injuries Centre at Iizuka City, Japan 
This centre is a beautiful modern two-storeyed hospital with a bed capacity of 150 beds, i.e. 75 beds for traumatic spinal lesions and 75 beds for spinal diseases.

A vocational sheltered workshop is located nearby for 50 paraplegics.

This centre is situated in the Northern Kyushu area of Japan which has a population of 6 million.

Planning for this centre's organisation and construction utilised many valuable suggestions from Dr J. J. Walsh (Great Britain), Professor V. Paeslack (Germany), Professor A. B. Rosier (U.S.A.), Dr Jos̄e Mendosa (Spain), Professor S. O. Brattgard (Sweden). 